\title{
Social disparities in parental smoking and young children's exposure to secondhand smoke at home: a time-trend analysis of repeated cross-sectional data from the German KiGGS study between 2003-2006 and 2009-2012
}

Benjamin Kuntz ${ }^{*}$ and Thomas Lampert

\begin{abstract}
Background: Children who are exposed to secondhand smoke (SHS) have an increased risk of a wide range of health problems and illnesses. Smoke-free legislation aims to improve indoor air quality and in this way protect the health of people who do not smoke. This paper examines trends in SHS exposure at home among children in Germany since the introduction of smoking bans in public places. Special focus is placed on the importance of the family of origin's socioeconomic status (SES) and on parental smoking behaviour.

Methods: The analyses are based on two waves of the "German Health Interview and Examination Survey for Children and Adolescents" (KiGGS) — one of which was conducted immediately before the introduction of central smoke-free legislation in the 2003-2006 period, the other approximately 6 years later from 2009 to 2012. A comparison is made between the answers given by the parents of children aged between 0 to 6 (KiGGS baseline study, $n=6680$; KiGGS Wave 1, $n=4455$ ). Domestic SHS exposure is covered in the parent interviews by asking whether anyone is allowed to smoke at home in the presence of their child. Parental smoking behaviour is determined separately for mothers and fathers. SES is determined on the basis of the parents' education, occupational status and income.

Results: The percentage of 0- to 6-year-old children exposed to SHS in the parental home fell from 23.9 to $6.6 \%$ in the period from 2003-2006 to 2009-2012. At the same time, the percentage of children with at least one parent who smokes decreased from 49.8 to $41.8 \%$. While relative social inequalities in parental smoking behaviour have tended to increase over time, inequalities in domestic SHS exposure have persisted. Children whose parents smoke and children from low-SES families are still most likely to be exposed to tobacco smoke. In both study periods and after statistical adjustment for parental smoking behaviour, children with a low SES had a 6.6-fold higher risk for SHS exposure in the parental home than children from high-SES households.

(Continued on next page)
\end{abstract}

\footnotetext{
* Correspondence: b.kuntz@rki.de

Department of Epidemiology and Health Monitoring, Robert Koch Institute,

General-Pape-Straße 62-64, Berlin 12101, Germany
} 
(Continued from previous page)

Conclusions: The results of the KiGGS study show that the proportion of children in Germany who are exposed to SHS at home has declined significantly over the last few years. There is much to suggest that the smoke-free legislation that has been introduced in Germany has led to a heightened awareness of the health risks of SHS both in public and in the private sphere, as well as to a denormalization of smoking. Children whose parents smoke, and among them particularly children from socially disadvantaged families, should be recognised as key target groups when implementing future tobacco-control measures.

Keywords: Secondhand smoke (SHS) exposure, Environmental tobacco smoke (ETS), Children, Parental smoking, Socioeconomic position, Health inequalities, KiGGS, Germany, Smoke-free legislation, Tobacco control

\section{Background}

Tobacco smoke is the most important avoidable indoor air pollutant [1, 2]. In 2004 an estimated 600,000 people worldwide died of diseases caused by prolonged exposure to secondhand smoke (SHS) [3]. About $28 \%$ of these deaths occurred in children under the age of 15 [3]. Cases of Sudden Infant Death Syndrome (SIDS), of which SHS exposure is a key risk factor $[4,5]$, were even not included in this study [3]. Children who are regularly exposed to SHS are more likely to suffer from respiratory complaints, asthma and infections of the lower respiratory tract [4, 6-9]. Middle-ear infections are also more prevalent among SHS-exposed children [10]. Furthermore, children whose parents or siblings smoke are more likely to start smoking as adolescents [11]. The diseases and deaths caused by SHS generate high economic costs and health-sector expenditure [12-14].

In the case of children, it must also be taken into account that they have a higher respiratory rate than adults, that their organs react particularly sensitively to environmental pollutants such as tobacco smoke during growth and maturation processes, and that their body's detoxification system is not yet fully developed [4, 7]. Whereas adult non-smokers can at least to some extent ensure a smoke-free environment for themselves, children are frequently exposed to SHS with no protection [15]. In addition, compared to adolescents and adults, children have limited control over their indoor environment and spend much of their time in closed rooms [16]. Private homes, and above all the parental home, are therefore the main places where children are exposed to SHS $[3,15,17,18]$.

In order to offer both children and non-smoking adolescents and adults better protection from the health risks of SHS, far-reaching laws to protect non-smokers have been introduced in recent years in Germany and in most other European countries [19-21]. An essential point of reference in this context is Article 8 of the World Health Organization's Framework Convention on Tobacco Control (FCTC), which calls for the comprehensive protection of the population against SHS [22, 23]. After changes to Germany's Workplace Ordinance led to extensive bans on smoking at the workplace in 2004, nationwide smoking bans in public buildings, railway stations and on public transport came into force in 2007. Laws to protect non-smokers were enacted in Germany's 16 federal states in 2007 and 2008, prohibiting smoking in public amenities, in healthcare, cultural, sporting and educational facilities, as well as in catering establishments. Exceptions for pubs, restaurants and cafés, however, still stand in the way of a comprehensive protection of non-smokers in most of Germany's states [24].

The smoking bans implemented as part of legislation to protect non-smokers have indeed led to a marked reduction in SHS exposure in public spaces and to a fall in the prevalence of SHS-associated diseases [25-27]. The effects on the unregulated private sphere are less unequivocal. The impact of smoke-free legislation on adult smoking behaviour on private premises-and thus also on the exposure of the non-smoking population to SHS on those premises-is the subject of controversial discussion. The displacement hypothesis (or last refuge model) postulates that it leads to a kind of evasive manoeuvre, i.e. the more smoking is banned in public, the more people will smoke at home [28-30]. By contrast, the social diffusion hypothesis holds that smoking bans in public places also have a knock-on effect on the private sphere. If non-smoking increasingly becomes the social norm and there is a greater overall awareness of the health risks of smoking and SHS, then more smokers will be encouraged to give up smoking altogether, or at least to cut it down, in the non-regulated private sector too $[28,29]$. In line with health behaviour change theories and models (e.g. Bronfenbrenner's socio-ecological model or the Behavioral Ecological Model (BEM)), both hypotheses acknowledge that environmental factors and social norms might influence parental smoking behaviour and thus children's SHS exposure in the home [31, 32].

According to studies, parental smoking behaviour and the family's socioeconomic position are the two key determinants when it comes to the domestic exposure of children to SHS [33-37]. Children whose parents smoke 
are also disproportionately more frequently exposed to SHS at home than the children of non-smoking parents $[35,36]$. When indicators of parental socioeconomic status (SES) are taken into consideration, it transpires that children from socially disadvantaged families are exposed to SHS much more frequently than children from families that are socially better off [33-35, 38, 39]. Social inequalities in parental tobacco use could partly explain SES differences in children's SHS exposure at home. In Germany, as in many other high income countries, smoking is more prevalent among lower SES groups [40-42].

This paper examines the development of levels of domestic SHS exposure among children in Germany after the introduction of smoke-free legislation in public places. It analyses both the importance of SES and the influence of parental smoking behaviour-as well as their mutual interactions-on SHS exposure over time. The aim is to find answers to the following four research questions:

1. How did the domestic SHS exposure of 0- to 6-yearold children develop in the period from 2003-2006 to 2009-2012?

2. How great is the influence of parental smoking behaviour on the SHS exposure of children?

3. To what extent are there social disparities in parental smoking behaviour and in SHS exposure among children, and what changes have taken place in these areas over time?

4. To what extent can parental smoking behaviour help explain social disparities in SHS exposure among children?

\section{Methods}

\section{Study population}

The "German Health Interview and Examination Survey for Children and Adolescents" (KiGGS) is part of the health monitoring system run on behalf of the German Federal Ministry of Health by the Robert Koch Institute (RKI), the national public health institute. The KiGGS study is a combined cross-sectional and cohort study; its objectives, concept and design are described in detail elsewhere [43-46]. KiGGS aims to regularly provide prevalence data collected nationwide on the health situation of children and adolescents living in Germany, focusing on the $0-17$ age group. The KiGGS baseline study (2003-2006) comprised interviews, physical examinations and laboratory analyses; the first follow-up survey, KiGGS Wave 1 (2009-2012), was carried out as a telephone-based survey. The KiGGS baseline study was a pure cross-sectional study with a total of 17,641 subjects aged between 0 and 17; the response rate was $66.6 \%$. Those invited to participate were randomly drawn from the population registers in a stratified random sample of 167 locations in Germany [44]. The sample of KiGGS Wave 1 consisted firstly of a new crosssection sample of 0 - to 6-year-olds who were again drawn at random from the population registers of the original study locations. Secondly, the former participants in the KiGGS baseline study were invited to take part in the new survey (KiGGS cohort). A total of 12,368 children and adolescents in the $0-17$ age range relevant for the cross-section took part; 4455 of these were invited for the first time (response $38.8 \%$ ), and 7913 were invited again (response $72.9 \%$ ) [46]. In this paper, timetrend analysis is solely based on repeated cross-sectional data.

\section{Ethical considerations}

Before the study began, votes of approval had been obtained from the Ethics Commission of Charite University Hospital Berlin, and Germany's Federal Commissioner for Data Protection; an interview was only carried out after either the subjects themselves (in the case of adults) or the persons having care and custody (in the case of minors) had been informed and had given their consent in writing.

\section{Domestic exposure to secondhand smoke}

The analyses on domestic SHS exposure are limited to the survey replies of the parents of children aged 0 to 6 years. The information on 6680 children from the KiGGS baseline study and the data of 4455 boys and girls from KiGGS Wave 1 are analysed (Table 1). The question asked was: "Is anybody allowed to smoke at home in the presence of your child and, if so, how often?" (answer categories: "Daily", "Several times a week", "Once a week", "Less often", "Never"). For this paper, the first four answer categories indicating regular or at least occasional exposure to SHS will be treated as one [47]. No modifications were made in either the question or the default answer categories between the KiGGS baseline study and KiGGS Wave 1 . This means that, allowing for the changed survey mode (written vs. telephone survey), statements can be made on the development of domestic SHS exposure over time.

\section{Parental smoking behaviour}

The interviews of the parents also collected information on the current smoking behaviour of both parents. The question asked was whether the father or mother currently smokes (answer categories: "Yes, daily", "Yes, sometimes", "No"), although no distinction is made between daily and occasional tobacco use in the following (Table 1). In order to investigate any cumulative effect of parental smoking behaviour on domestic SHS exposure, a new three-stage variable was formed from the 
Table 1 Characteristics of the KiGGS study population with regard to children aged 0 to 6 years

\begin{tabular}{|c|c|c|c|c|c|}
\hline & & KiGGS & (2003-06) & KiGGS & 09-12) \\
\hline & & $\overline{(n=66}$ & & $(n=44$ & \\
\hline & & $\mathrm{n}^{\mathrm{a}}$ & $\%^{\mathrm{b}}$ & $\mathrm{n}^{\mathrm{a}}$ & $\%^{\mathrm{b}}$ \\
\hline Age (years) & 0 & 935 & 11.6 & 634 & 11.6 \\
\hline & 1 & 925 & 14.4 & 641 & 14.3 \\
\hline & 2 & 945 & 14.8 & 667 & 14.8 \\
\hline & 3 & 934 & 14.8 & 601 & 14.8 \\
\hline & 4 & 982 & 14.5 & 663 & 14.5 \\
\hline & 5 & 953 & 14.8 & 633 & 14.8 \\
\hline & 6 & 1006 & 15.1 & 616 & 15.2 \\
\hline Sex & Boys & 3367 & 51.3 & 2290 & 51.3 \\
\hline & Girls & 3313 & 48.7 & 2165 & 48.7 \\
\hline Socioeconomic status (SES) & Low & 1023 & 19.6 & 359 & 17.5 \\
\hline & Medium & 3926 & 58.4 & 2685 & 59.2 \\
\hline & High & 1654 & 22.0 & 1409 & 23.3 \\
\hline & Missings & 77 & - & 2 & - \\
\hline Domestic secondhand smoke exposure & Daily & 465 & 8.9 & 52 & 2.4 \\
\hline & Several times a week & 155 & 2.8 & 10 & 0.2 \\
\hline & Once a week & 46 & 0.7 & 16 & 0.3 \\
\hline & Less often & 686 & 11.4 & 109 & 3.6 \\
\hline & Never & 5210 & 76.1 & 4266 & 93.4 \\
\hline & Missings & 118 & - & 2 & - \\
\hline Paternal smoking behaviour & Yes & 2593 & 42.0 & 1236 & 34.7 \\
\hline & No & 3778 & 58.0 & 2914 & 65.3 \\
\hline & Missings & 309 & - & 305 & - \\
\hline Maternal smoking behaviour & Yes & 1932 & 31.0 & 890 & 25.1 \\
\hline & No & 4661 & 69.0 & 3555 & 74.9 \\
\hline & Missings & 87 & - & 10 & - \\
\hline Parental smoking behaviour & Both parents smoke & 1256 & 21.0 & 484 & 15.4 \\
\hline & One parent smokes & 1809 & 28.7 & 1019 & 26.4 \\
\hline & Neither parent smokes & 3273 & 50.2 & 2638 & 58.2 \\
\hline & Missings & 342 & - & 314 & - \\
\hline
\end{tabular}

anweighted

${ }^{b}$ Percentages were calculated without missing values and weighted with regard to age, gender, region, nationality, type of municipality, and the education status of the head of the household (population structure in Germany 2009/2010)

information on the smoking behaviour of the mother and the father (categories: "Neither parent smokes", "One of the parents smokes", "Both parents smoke"). Children for whom valid data were not available on both parents' current smoking behaviour were excluded from the analyses on parental smoking behaviour (KiGGS baseline study: $n=342$, KiGGS Wave 1: $n=314$ ).

\section{Socioeconomic status (SES)}

SES is determined on the basis of an index developed by the RKI and frequently used in population-based studies in Germany [48-50]. This index contains information provided by the parents on their school education and vocational training, their occupational status and their income, making it possible to classify them in a low-, middle- or high-status group (Table 1). The individual dimensions of education and occupation were collected separately for each parent and the higher value used respectively for the overall index. Income was recorded as a characteristic of the household; the net equivalent income was calculated based on the number and age of the household members. Missing data on income were imputed using a regression model. In order to create the index, the status characteristics were first transformed 
into three metric subscales with a value range from 1.0 to 7.0. Then the point scores of the subscales were added to make a total score with a value range from 3.0 to 21.0. The classification into a low-, middle- or highstatus group is based on a distribution-based definition of five groups with equal numbers of members (quintiles); the middle three groups (from 2nd to 4th quintile) are combined. Detailed information on the measurement of SES in the KiGGS study has been published elsewhere [48].

\section{Statistical analyses}

All analyses were conducted with a weighting factor that corrects the sample's deviations from the population structure (figures for 31 December 2010) with regard to age, gender, region, nationality, type of municipality, and the education status of the head of the household [46]. Reports are made on prevalences with $95 \%$ confidence intervals, taking differences in SES and parental smoking behaviour into account. With a view to possible differences in the distribution of domestic SHS exposure, odds ratios (OR) are also reported; these were calculated using binary logistic regressions. Odds ratios indicate the factor by which the statistical chance of domestic SHS exposure is increased in children with a low SES or with parents who smoke, compared to children with a high SES or with non-smoking parents respectively.

In order to take into account both the weighting and the correlation of the participants within a municipality, the confidence intervals and $\mathrm{p}$-values were calculated using procedures for complex samples. Group differences were checked for significance according to RaoScott using the chi-square test for complex samples corrected via the $F$ distribution [51]. Differences are regarded as statistically significant if the confidence intervals do not overlap or if the probability of error (p) takes on a value smaller than 0.05 . All the analyses were performed using the IBM SPSS Statistics Version 20 software product.

\section{Results}

The percentage of 0 - to 6-year-old children who are exposed to SHS in the parental home fell from 23.9 to $6.6 \%$ in the period from 2003-2006 to 2009-2012. The proportion of children with parents who smoke also decreased - although not by quite as much. According to the data from KiGGS Wave 1, $41.8 \%$ of children in 2009-2012 had at least one parent who smoked (down from $49.8 \%$ in 2003-2006), and both parents smoked in the case of 15.4 \% (2003-2006: $21.0 \%)$ of children (Fig. 1). As Table 1 shows, the percentage of both fathers and mothers who smoke has declined over time.

Children whose parents smoke are significantly more affected by SHS exposure than children whose parents do not smoke. In the 2003-2006 period, $52.3 \%$ of children with two smoking parents, $30.2 \%$ of children with one smoking parent, and $5.6 \%$ of children with no smoking parent were exposed to tobacco smoke at home. In the 2009-2012 period, the corresponding percentage in each of the three groups was considerably lower at $14.9,10.2$ and $1.6 \%$ respectively. The relative decline in SHS exposure was thus about the same for children of smoking parents as for children whose parents do not smoke.

Children with a low SES are more frequently exposed to SHS in the parental home and more likely to have parents who smoke than children with a high SES (Figs. 2 and 3). However, declining prevalences in domestic SHS

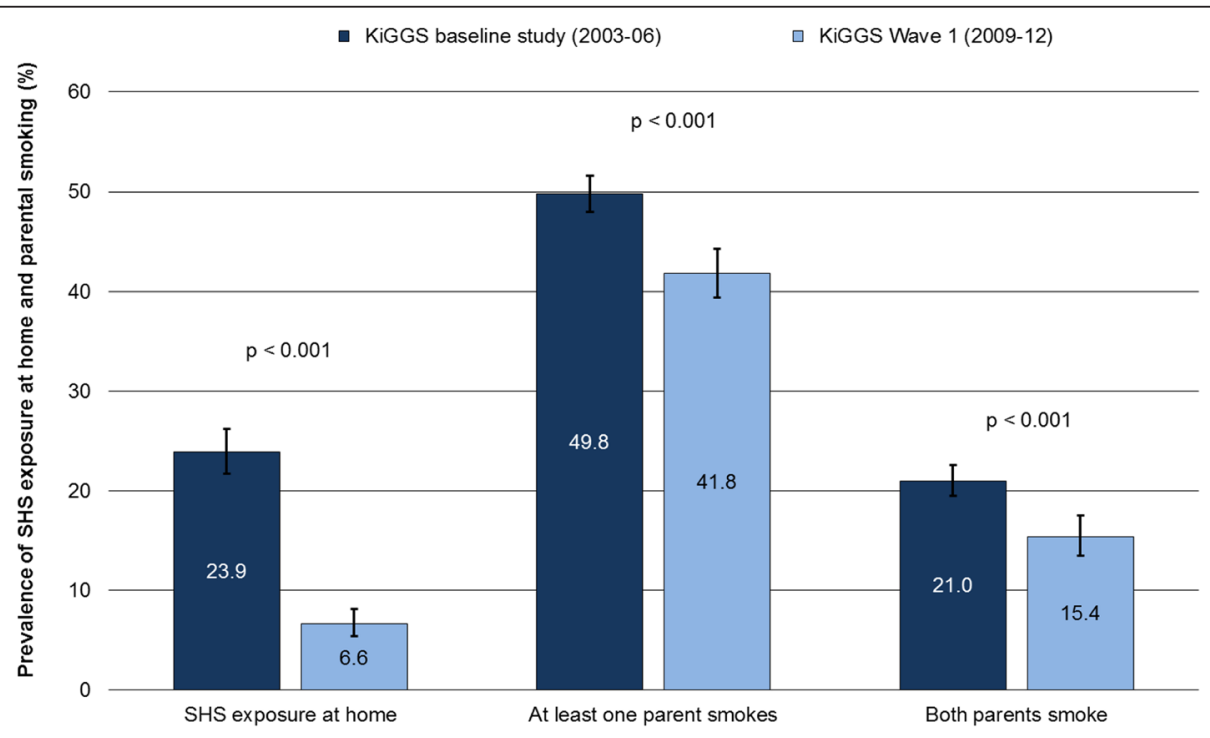

Fig. 1 Secondhand smoke (SHS) exposure at home and parental smoking behaviour among 0- to 6-year-old children in Germany 


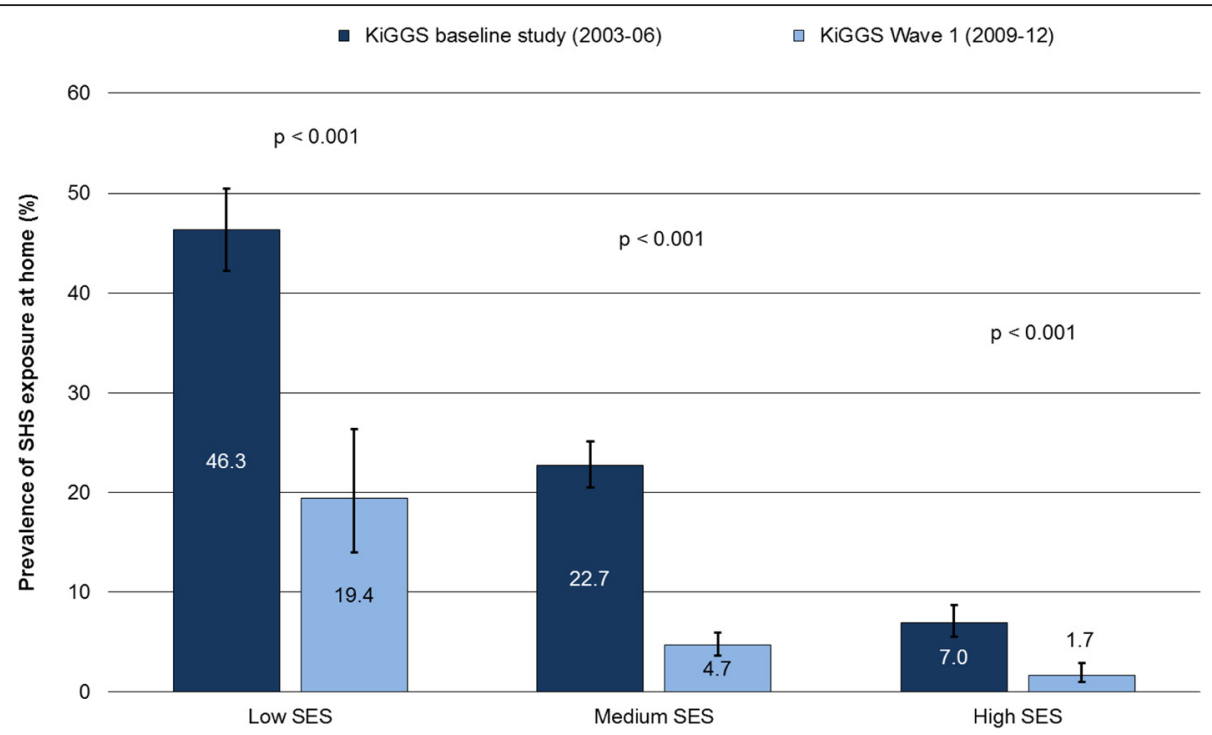

Fig. 2 Secondhand smoke (SHS) exposure at home by socioeconomic status (SES) among 0- to 6-year-old children in Germany

exposure can be observed in children of all status groups (Fig. 2). On the other hand, the proportion of children whose parents smoke has only decreased to a statistically significant extent among those from the middle- and high-status groups (Fig. 3). As a result, at least the relative social inequalities have increased over time.

When stratified according to parental smoking behaviour, the analyses indicate that, according to the data from KiGGS Wave 1, social disparities in the levels of SHS exposure only still apply to children whose parents smoke (Fig. 4). In the KiGGS baseline study there had also been a marked social gradient in domestic SHS exposure among children whose parents do not smoke, meaning that household and family members or visitors were much more likely to be allowed to smoke - even in the presence of the children - in the homes of socially disadvantaged parents than in the homes of parents who were socially better off (9.8 vs. $1.8 \%$ ). In the KiGGS baseline study, of all children with smoking parents those with a low SES were exposed much more often to SHS in the parental home than children with a middle SES, and the latter, in turn, more often than children with a high SES; in KiGGS Wave 1, by contrast, significant disparities only existed between children with a low and high SES and between children with a low and middle SES. In the case of children with at least one smoking parent, although the percentage of those who are exposed to SHS at home has also more than halved

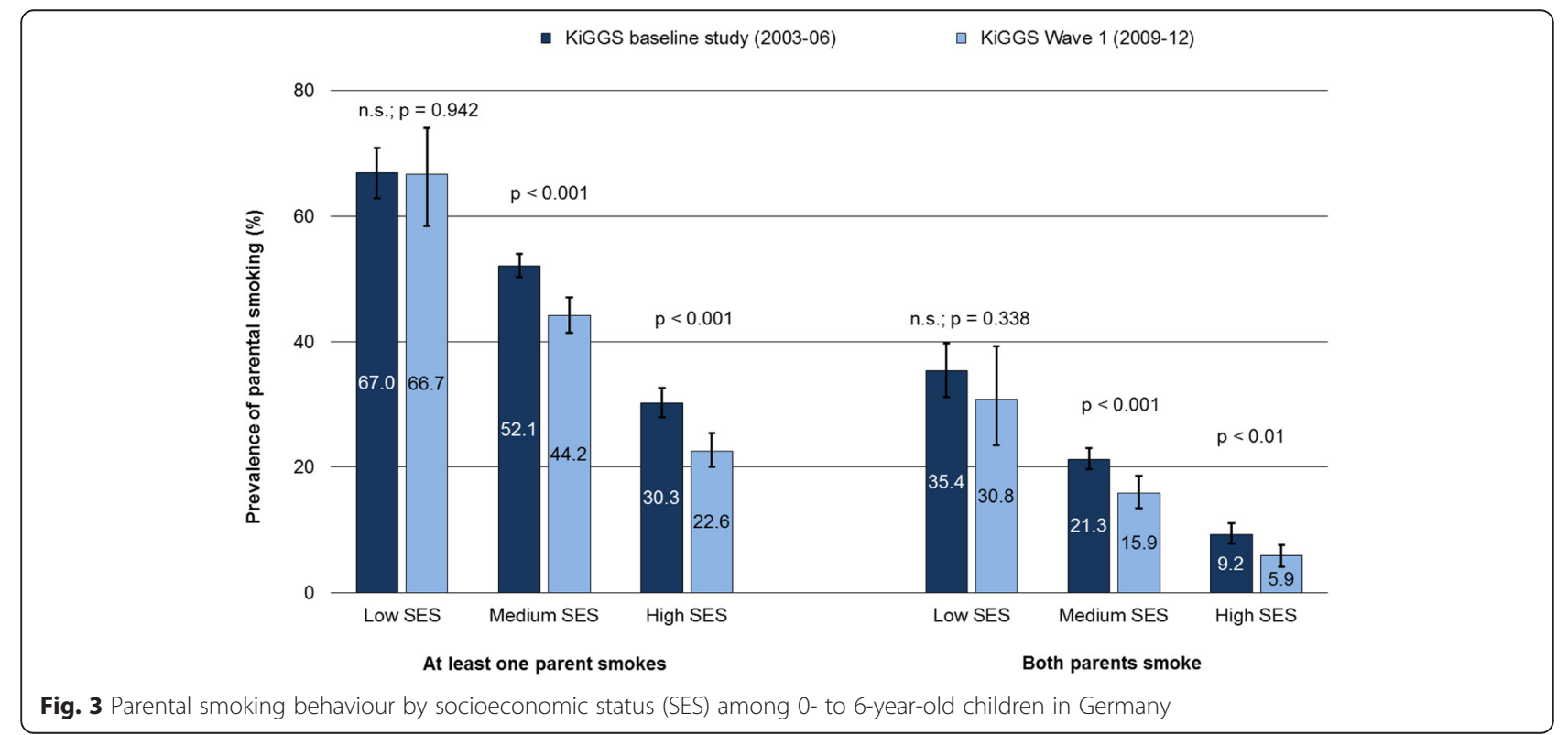




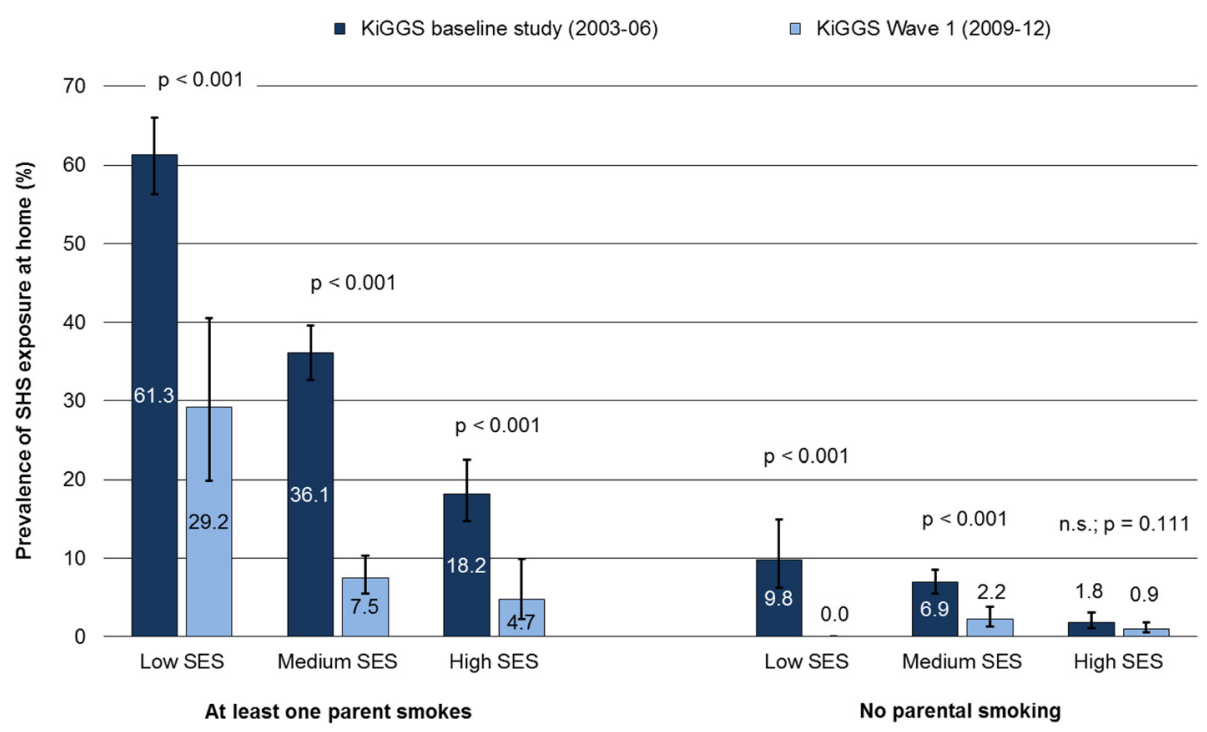

Fig. 4 Secondhand smoke (SHS) exposure at home by socioeconomic status (SES) among 0- to 6-year-old children in Germany, stratified by parental smoking behaviour

in the low-status group over time, the relative decline in SHS exposure was even more pronounced in the middle- and high-status groups (Fig. 4).

As the multivariate analysis shows, both SES and parental smoking behaviour are associated with the SHS exposure of 0 - to 6-year-old children - each factor independently of each other (Table 2). A comparison of the two analytical models reveals that the association between SES and the domestic exposure of children to SHS is reduced by about half when parental smoking behaviour is taken into account. Vice versa, the SES explains about a quarter of the association between parental smoking behaviour and domestic SHS exposure among children. Even taking into account the fact that children from socially disadvantaged families are more likely to have parents who smoke (Fig. 3), the data from KiGGS Wave 1 indicate that children with a low SES have a 6.6-fold higher risk for SHS exposure in the parental home than children with a high SES. Even children with a middle SES still have a 1.7-fold higher risk,

Table 2 Domestic secondhand smoke (SHS) exposure among 0- to 6-year-old children in Germany by socioeconomic status (SES) and parental smoking behaviour

\begin{tabular}{|c|c|c|c|c|}
\hline & \multicolumn{2}{|c|}{ KiGGS baseline study (2003-2006) } & \multicolumn{2}{|c|}{ KiGGS Wave 1 (2009-2012) } \\
\hline & Model 1 & Model 2 & Model 1 & Model 2 \\
\hline & OR (95\% Cl) & OR $(95 \%$ Cl) & OR $(95 \%$ Cl) & OR $(95 \% \mathrm{Cl})$ \\
\hline & $p$ value & $p$ value & $p$ value & $p$ value \\
\hline \multicolumn{5}{|l|}{ Socioeconomic status (SES) } \\
\hline \multirow[t]{2}{*}{ Low } & $11.63(9.11-14.85)$ & $6.58(4.97-8.71)$ & $13.59(7.03-26.28)$ & $6.59(3.17-13.68)$ \\
\hline & $p<0.001$ & $p<0.001$ & $p<0.001$ & $p<0.001$ \\
\hline \multirow[t]{2}{*}{ Medium } & $3.93(3.11-4.96)$ & $2.76(2.10-3.62)$ & $2.77(1.54-5.00)$ & $1.73(0.94-3.20)$ \\
\hline & $p<0.001$ & $p<0.001$ & $p<0.001$ & $p=0.080$ \\
\hline High & Ref. & Ref. & Ref. & Ref. \\
\hline \multicolumn{5}{|l|}{ Parental smoking behaviour } \\
\hline \multirow[t]{2}{*}{ Both parents smoke } & $19.10(15.38-23.73)$ & $15.29(12.21-19.13)$ & $11.08(5.90-20.80)$ & 7.40 (3.78-14.48) \\
\hline & $p<0.001$ & $p<0.001$ & $p<0.001$ & $p<0.001$ \\
\hline \multirow[t]{2}{*}{ One parent smokes } & $7.43(5.98-9.23)$ & $6.53(5.21-8.17)$ & $7.08(4.01-12.50)$ & $5.55(3.16-9.75)$ \\
\hline & $p<0.001$ & $p<0.001$ & $p<0.001$ & $p<0.001$ \\
\hline Neither parent smokes & Ref. & Ref. & Ref. & Ref. \\
\hline
\end{tabular}

Model 1: adjusted for age and sex of the child, Model 2: + mutually adjusted for SES and parental smoking behaviour; bold = significant at .05 level; Results of the KiGGS baseline study and KiGGS Wave 1 were adjusted to the population structure in Germany 2009/2010 
although this is not statistically significant. The corresponding odds ratios were 6.6 and 2.8 respectively in the KiGGS baseline study. Vice versa, after statistical adjustment for SES, a child is about 5.6 and 7.4 times more likely to be exposed to SHS at home if one or both parents smoke than if neither of them smoke. In the KiGGS baseline study, the corresponding odds ratios were even higher at 6.5 and 15.3 respectively.

\section{Discussion}

The results of the KiGGS study show that the percentage of 0- to 6-year-old children in Germany who are exposed to SHS in the parental home has declined by more than half over the last few years. This is all the more remarkable in view of the fact that the proportion of children whose parents smoke has not fallen to the same extent. It seems that both non-smoking parents and parents who themselves smoke are increasingly making sure that no one smokes in the presence of their children at home.

Our findings are in line with international study results on the development of children's domestic exposure to SHS over time. Current studies from the UK [18, 52-54], Denmark [34], the USA [55, 56], Australia [57] and Japan [38] indicate that the percentage of children who are exposed to SHS at home has decreased noticeably over the last few years, in some cases immediately after the introduction of laws to protect non-smokers. In a comparison of 3 years of school enrolment -2004 / $2005,2005 / 2006$ and 2008/2009 - regional study results in Bavaria show that the percentage of 5- to 6-year-old children from homes where people smoke has at least not increased [17]. The available results thus indicate that the introduction of smoking bans in public places has not led to people smoking more at home, as some experts had feared [30]. Rather, the findings can be interpreted according to the social diffusion hypothesis, which states that smoke-free legislation can also have positive effects on hitherto unregulated areas such as private households [28, 29].

The KiGGS results confirm for both study periods the finding (which is well known from literature) that parents who smoke must be regarded as the main source of domestic SHS exposure among children $[35,36]$. Whereas more than half of children whose parents both smoked were exposed to SHS at home in 2003-2006, this figure had fallen to about $15 \%$ by 2009-2012. In the case of children whose parents are both non-smokers, the already small proportion of those who are exposed to SHS at home (e.g. by the tobacco consumption of other household members or visitors) also fell significantly from 5.6 to $1.6 \%$.

That children from socially disadvantaged families have a higher risk of exposure to SHS at home has been documented several times both in Germany [33, 58-61] and internationally [35, 38, 39, 52, 54, 57, 62, 63]. As our analyses show, the relative decline in SHS exposure has been equally strong in all status groups, i.e. there has been no increase in relative social inequalities in the domestic exposure of children to SHS. This result is consistent with the findings of a regional study in Bavaria [17] and several international studies [53, 54]. However, other studies document an increase in relative social inequalities in the field of SHS exposure among children $[38,57]$. According to the KiGGS data, there has been an increase in the relative social inequalities relating to parental smoking behaviour, since the percentage of children whose parents smoke has only declined to a statistically significant extent in the middle- and high-status groups. Our results thus confirm study findings from Germany and other industrialized countries, most of which consistently show that socioeconomic inequalities in smoking among adults have increased over the last 20 years [41, 64-67]. Social disparities in smoking behaviour and in SHS exposure can be found in different age and population groups. Already published results of the KiGGS study suggest that significant social disparities also exist in relation to maternal smoking during pregnancy [68] as well as in daily tobacco consumption and in the SHS exposure of 11- to 17-year-old adolescents [69].

\section{Limitations}

Our results are based on a nationwide, representative data basis. The informative value of the findings is, however, limited by the fact that the data on parental smoking behaviour and children's SHS exposure in the parental home are based on information provided by the respondents themselves. Socially desired response behaviour - leading to lower figures for the actual percentage of parents who smoke and for the number of children who are exposed to SHS-cannot therefore be ruled out (social desirability bias). In KiGGS Wave 1 it was not possible to carry out measurements of air pollutant levels in rooms or to take samples to determine levels of cotinine (a metabolite of nicotine) in children's saliva, urine or blood-as have been carried out in other studies $[39,54-56,61,62]$ to quantify the true levels of SHS exposure.

As described in the methods section, children for whom valid data were not available on both parents' current smoking behaviour were excluded from all the analyses in which parental smoking behaviour was considered-as in a similar study [38]. However, these are often children of single parents (usually mothers). Since it is known from literature that an above-average number of single parents are smokers [70-72], we conducted additional analyses in which the family type was taken 
into account (results not shown). In line with current research, these revealed that the 0- to 6-year-old children of single parents are more frequently exposed to SHS at home than peers who live in two-parent families (KiGGS baseline study: 44.5 vs. $22.0 \%$; KiGGS Wave 1: 13.4 vs. $5.9 \%)$. This is most likely due to the fact that it is rarer for children who grow up in two-parent families to have smoking mothers than children of single parents (KiGGS baseline study: 28.3 vs. $57.8 \%$; KiGGS Wave 1: 22.7 vs. $46.9 \%$ ). Yet here, too, there are declining prevalences in both groups, despite the differences between the groups.

Finally, the change in the survey mode that took place between the KiGGS baseline study and KiGGS Wave 1 must also be taken into account [46]. In the baseline study, the data on parental smoking behaviour and SHS exposure in the parental home were collected using selfcompleted questionnaires; by contrast, computer-aided telephone interviews were used in the follow-up survey. Since the tendency towards social desirability has occasionally been seen to be greater in interviews than in written surveys [73, 74], the possibility cannot be excluded that the downward trend in parental smoking behaviour and domestic SHS exposure among children might be based at least partially on a "mode effect". Whether such an effect does indeed exist, and how parental smoking behaviour and domestic SHS exposure among children will develop in the future, cannot be estimated on the basis of the KiGGS data until 2017 at the earliest. Written questionnaires will again be used in KiGGS Wave 2, whose field phase will last about 3 years (2014-2017) [75].

\section{Conclusions}

In Germany, the prevalence of SHS exposure at home among children has declined markedly over the last few years. The percentage of children whose parents smoke has also fallen. There is much to suggest that the smoke-free legislation that has been introduced in Germany has led to a heightened awareness of the health risks of SHS both in public and in the private sphere, as well as to a denormalization of smoking. While relative social inequalities in parental smoking behaviour have tended to increase over time, inequalities in domestic SHS exposure have persisted. Children whose parents smoke - and among them in particular children from socially disadvantaged families - should be recognised as key target groups when implementing future tobaccocontrol measures.

\section{Abbreviations}

FCTC, World Health Organization's Framework Convention on Tobacco Control; KiGGS, German Health Interview and Examination Survey for Children and Adolescents; RKI, Robert Koch Institute; SES, socioeconomic status; SHS, secondhand smoke; SIDS, Sudden Infant Death Syndrome

\section{Acknowledgements}

The authors thank all participants and their parents for participating as well as all the colleagues at the Robert Koch Institute that were involved in conducting the study.

\section{Funding}

The KiGGS study was funded by the German Federal Ministry of Health, the Ministry of Education and Research, and the Robert Koch Institute.

\section{Availability of data and materials}

The authors confirm that, for approved reasons, some access restrictions apply to the data underlying these findings. Informed consent from study participants did not cover public deposition of data. However, the KiGGS data can be accessed for scientific use upon request at www.rki.de.

\section{Authors' contributions}

BK and TL conceptualized the study. BK performed the literature search, analysed the data and wrote the first draft of the manuscript. TL contributed to the interpretation of the findings and the critical revision of the paper. Both authors read and approved the final manuscript.

\section{Competing interests}

The authors declare that they have no competing interests.

\section{Consent for publication}

Not applicable.

\section{Ethics approval and consent to participate}

Before the study began, votes of approval had been obtained from the Ethics Commission of Charité University Hospital Berlin, and Germany's Federal Commissioner for Data Protection; an interview was only carried out after either the subjects themselves (in the case of adults) or the persons having care and custody (in the case of minors) had been informed and had given their consent in writing.

Received: 21 January 2016 Accepted: 24 May 2016

Published online: 08 June 2016

\section{References}

1. International Agency for Research on Cancer. IARC monographs on the evaluation of carcinogenic risks to humans. Volume 83: tobacco smoke and involuntary smoking. Lyon: IARC; 2004.

2. USDHHS. The health consequences of involuntary exposure to tobacco smoke: a report of the Surgeon General. Atlanta: U.S. Department of Health and Human Services, Centers for Disease Control and Prevention, Coordinating Center for Health Promotion, National Center for Chronic Disease Prevention and Health Promotion, Office on Smoking and Health; 2006.

3. Öberg M, Jaakkola MS, Woodward A, Peruga A, Prüss-Ustün A. Worldwide burden of disease from exposure to second-hand smoke: a retrospective analysis of data from 192 countries. Lancet. 2011;377(9760):139-46.

4. Treyster Z, Gitterman B. Second hand smoke exposure in children: environmental factors, physiological effects, and interventions within pediatrics. Rev Environ Health. 2011;26(3):187-95.

5. Tobacco Advisory Group of the Royal College of Physicians. Report on passive smoking and children. London: RCP; 2010.

6. ASH Research Report, editors. Secondhand smoke: the impact on children. http://www.ash.org.uk/files/documents/ASH_596.pdf; 2014.

7. Polanska K, Hanke W, Ronchetti R, van den Hazel P, Zuurbier M, Koppe JG, Bartonova A. Environmental tobacco smoke exposure and children's health. Acta Paediatr Suppl. 2006;95(453):86-92.

8. Jarosinska D, Polanska K, Wojtyniak B, Hanke W. Towards estimating the burden of disease attributable to second-hand smoke exposure in Polish children. Int J Occup Med Environ Health. 2014;27(1):38-49.

9. Been JV, Millett C, Lee JT, van Schayck CP, Sheikh A. Smoke-free legislation and childhood hospitalisations for respiratory tract infections. Eur Respir J. 2015;46(3):697-706

10. Yilmaz G, Caylan N, Karacan C. Effects of active and passive smoking on ear infections. Curr Infect Dis Rep. 2012;14(2):166-74.

11. Leonardi-Bee J, Jere ML, Britton J. Exposure to parental and sibling smoking and the risk of smoking uptake in childhood and adolescence: a systematic review and meta-analysis. Thorax. 2011;66(10):847-55. 
12. Max W, Sung HY, Shi Y. Deaths from secondhand smoke exposure in the United States: economic implications. Am J Public Health. 2012;102(11):2173-80.

13. Batscheider A, Zakrzewska S, Heinrich J, Teuner CM, Menn P, Bauer CP, Hoffmann U, Koletzko S, Lehmann I, Herbarth O, et al. Exposure to secondhand smoke and direct healthcare costs in children - results from two German birth cohorts, GINIplus and LISAplus. BMC Health Serv Res. 2012;12:344.

14. Mason J, Wheeler W, Brown MJ. The economic burden of exposure to secondhand smoke for child and adult never smokers residing in U.S. public housing. Public Health Rep. 2015;130(3):230-44.

15. Ashley MJ, Ferrence R. Reducing children's exposure to environmental tobacco smoke in homes: issues and strategies. Tob Control. 1998;7(1):61-5.

16. Mbulo L, Palipudi KM, Andes $L$ et al. Secondhand smoke exposure at home among one billion children in 21 countries: findings from the Global Adult Tobacco Survey (GATS). Tob Control 2016 (in press).

17. Bolte $\mathrm{G}$, Wildner M, Fromme H. Auswirkung der Nichtraucherschutzgesetzgebung auf die Tabakrauchbelastung von Kindern und auf soziale Ungleichheiten in der Exposition. prävention. Zeitschrift für Gesundheitsförderung. 2015;38(1):7-9.

18. Akhtar PC, Haw SJ, Currie DB, Zachary R, Currie CE. Smoking restrictions in the home and secondhand smoke exposure among primary schoolchildren before and after introduction of the Scottish smoke-free legislation. Tob Control. 2009;18(5):409-15.

19. Schaller K, Pötschke-Langer M. Tobacco control in Germany and Europe profits and pitfalls. Atemwegs- und Lungenkrankheiten. 2015;41(8):372-80.

20. Kuntz B, Zeiher J, Lampert T. Tabak - Zahlen und Fakten zum Konsum. In: Deutsche Hauptstelle für Suchtfragen e.V, editor. Jahrbuch Sucht 2016. Lengerich: Pabst; 2016. p. 55-87.

21. Pötschke-Langer M. Passive smoking: 6 years of the non-smoker protection act in Germany and the consequences. Radiologe. 2014;54(2):156-7.

22. Word Health Organization. WHO framework convention on tobacco control. Geneva: WHO; 2003.

23. Hyland A, Barnoya J, Corral JE. Smoke-free air policies: past, present and future. Tob Control. 2012;21(2):154-61.

24. Deutsches Krebsforschungszentrum, editor. Tobacco atlas Germany 2015. Lengerich: Pabst Science Publishers; 2015.

25. International Agency for Research on Cancer. Evaluating the Effectiveness of Smoke-free Policies. IARC Handbooks of Cancer Prevention, Volume 13. Lyon: IARC; 2009.

26. Been JV, Nurmatov UB, Cox B, Nawrot TS, van Schayck CP, Sheikh A. Effect of smoke-free legislation on perinatal and child health: a systematic review and meta-analysis. Lancet. 2014;383(9928):1549-60.

27. Frazer K, Callinan JE, McHugh J, van Baarsel S, Clarke A, Doherty K, Kelleher C. Legislative smoking bans for reducing harms from secondhand smoke exposure, smoking prevalence and tobacco consumption. Cochrane Database Syst Rev. 2016;2:CD005992.

28. Borland $\mathrm{R}$, Yong $\mathrm{H}-\mathrm{H}$, Cummings KM, Hyland A, Anderson S, Fong GT. Determinants and consequences of smoke-free homes: findings from the International Tobacco Control (ITC) Four Country Survey. Tob Control. 2006; 15 suppl 3:iii42-50.

29. Mons U, Nagelhout GE, Allwright S, Guignard R, van den Putte B, Willemsen MC, Fong GT, Brenner H, Potschke-Langer M, Breitling LP. Impact of national smoke-free legislation on home smoking bans: findings from the International Tobacco Control Policy Evaluation Project Europe Surveys. Tob Control. 2013;22(e1):e2-9.

30. Ho SY, Wang MP, Lo WS, Mak KK, Lai HK, Thomas GN, Lam TH. Comprehensive smoke-free legislation and displacement of smoking into the homes of young children in Hong Kong. Tob Control. 2010;19(2):129-33.

31. Collins BN, Ibrahim J. Pediatric secondhand smoke exposure: systematic multilevel strategies to improve health. Glob Heart. 2012;7(2):161-65.

32. Hovell MF, Hughes SC. The behavioral ecology of secondhand smoke exposure: a pathway to complete tobacco control. Nicotine Tob Res. 2009; 11(11):1254-64.

33. Bolte G, Fromme H, GME Study Group. Socioeconomic determinants of children's environmental tobacco smoke exposure and family's home smoking policy. Eur J Public Health. 2009;19(1):52-8.

34. Pisinger $\mathrm{C}$, Hammer-Helmich $\mathrm{L}$, Andreasen $\mathrm{AH}$, Jorgensen $\mathrm{T}$, Glumer $\mathrm{C}$. Social disparities in children's exposure to second hand smoke at home: a repeated cross-sectional survey. Environ Health. 2012;11:65.

35. Orton S, Jones LL, Cooper S, Lewis S, Coleman T. Predictors of children's secondhand smoke exposure at home: a systematic review and narrative synthesis of the evidence. PLoS One. 2014;9(11):e112690.
36. Vitória PD, Machado JC, Araújo AC, Ravara SB, Samorinha C, Antunes H, Rosas M, Becoña E, Precioso J. Children's exposure to second hand smoke at home: a cross-sectional study in Portugal. Revista Portuguesa de Pneumologia (English Edition). 2015;21(4):178-84.

37. Turrell G, Battistutta D, McGuffog I. Social determinants of smoking among parents with infants. Aust N Z J Public Health. 2002;26(1):30-7.

38. Saito J, Tabuchi T, Shibanuma A, Yasuoka J, Nakamura M, Jimba M. 'Only fathers smoking' contributes the most to socioeconomic inequalities: changes in socioeconomic inequalities in infants' exposure to second handsmoke over time in Japan. PLoS One. 2015;10(10):e0139512.

39. Yi O, Kwon HJ, Kim D, Kim H, Ha M, Hong SJ, Hong YC, Leem JH, Sakong J, Lee $C G$, et al. Association between environmental tobacco smoke exposure of children and parental socioeconomic status: a cross-sectional study in Korea. Nicotine Tob Res. 2012;14(5):607-15.

40. Cavelaars AE, Kunst AE, Geurts JJ, Crialesi R, Grotvedt L, Helmert U, Lahelma E, Lundberg O, Matheson J, Mielck A, et al. Educational differences in smoking: international comparison. BMJ. 2000;320(7242):1102-07.

41. Giskes K, Kunst AE, Benach J, Borrell C, Costa G, Dahl E, Dalstra JA, Federico B, Helmert U, Judge K, et al. Trends in smoking behaviour between 1985 and 2000 in nine European countries by education. J Epidemiol Community Health. 2005;59(5):395-401.

42. Lampert T. Smoking, physical inactivity, and obesity: associations with social status. Dtsch Arztebl Int. 2010;107(1-2):1-7.

43. Hölling H, Schlack R, Kamtsiuris P, Butschalowsky H, Schlaud M, Kurth BM. The KiGGS study. Nationwide representative longitudinal and cross-sectional study on the health of children and adolescents within the framework of health monitoring at the Robert Koch Institute. Bundesgesundheitsblatt Gesundheitsforschung Gesundheitsschutz. 2012;55(6-7):836-42.

44. Kamtsiuris $P$, Lange M, Schaffrath Rosario A. The German Health Interview and Examination Survey for Children and Adolescents (KiGGS): sample design, response and nonresponse analysis. Bundesgesundheitsblatt Gesundheitsforschung Gesundheitsschutz. 2007:50(5-6):547-56.

45. Kurth BM, Kamtsiuris P, Hölling H, Schlaud M, Dölle R, Ellert U, Kahl H, Knopf H, Lange M, Mensink GB, et al. The challenge of comprehensively mapping children's health in a nation-wide health survey: design of the German KiGGSStudy. BMC Public Health. 2008;8:196.

46. Lange M, Butschalowsky HG, Jentsch F, Kuhnert R, Schaffrath Rosario A, Schlaud M, Kamtsiuris P, KiGGS Study Group. The first KiGGS follow-up (KiGGS Wave 1). Study conduct, sample design, and response. Bundesgesundheitsblatt Gesundheitsforschung Gesundheitsschutz. 2014;57(7):747-61.

47. Lampert T, Kuntz B, KiGGS Study Group. Growing up healthy - What significance does social status have? GBE kompakt 2015, 6(1). http://www.rki. de/EN/Content/Health_Monitoring/Health_Reporting/GBEDownloadsK/2015_ 1_growing_up_healthy.pdf?_blob=publicationFile. Accessed 10 May 2016.

48. Lampert T, Müters S, Stolzenberg H, Kroll LE, KiGGS Study Group. Measurement of socioeconomic status in the KiGGS study. First follow-up (KiGGS Wave 1). Bundesgesundheitsblatt Gesundheitsforschung Gesundheitsschutz. 2014;57(7):762-70.

49. Lampert T, Kroll LE, Müters S, Stolzenberg H. Measurement of the socioeconomic status within the German Health Update 2009 (GEDA). Bundesgesundheitsblatt Gesundheitsforschung Gesundheitsschutz. 2013;56(1):131-43.

50. Lampert T, Kroll L, Müters S, Stolzenberg H. Measurement of socioeconomic status in the German Health Interview and Examination Survey for Adults (DEGS1). Bundesgesundheitsblatt Gesundheitsforschung Gesundheitsschutz. 2013;56(5-6):631-6.

51. Rao JNK, Scott AJ. On simple adjustments to chi-square tests with sample survey data. Ann Stat. 1987;15(1):385-97.

52. Moore GF, Currie D, Gilmore G, Holliday JC, Moore L. Socioeconomic inequalities in childhood exposure to secondhand smoke before and after smoke-free legislation in three UK countries. J Public Health (Oxf). 2012;34(4):599-608.

53. Moore GF, Moore L, Littlecott HJ, Ahmed N, Lewis S, Sulley G, Jones E, Holliday J. Prevalence of smoking restrictions and child exposure to secondhand smoke in cars and homes: a repeated cross-sectional survey of children aged 10-11 years in Wales. BMJ Open. 2015;5(1):e006914.

54. Jarvis MJ, Feyerabend C. Recent trends in children's exposure to second-hand smoke in England: cotinine evidence from the Health Survey for England. Addiction. 2015;110(9):1484-92.

55. Homa DM, Neff LJ, King BA, Caraballo RS, Bunnell RE, Babb SD, Garrett BE, Sosnoff CS, Wang L, Centers for Disease C, et al. Vital signs: disparities in nonsmokers' exposure to secondhand smoke-United States, 1999-2012. MMWR Morb Mortal Wkly Rep. 2015;64(4):103-8. 
56. Jain RB. Trends in exposure to second hand smoke at home among children and nonsmoker adolescents. Sci Total Environ. 2016;542(Part A): 144-52.

57. Gartner CE, Hall WD. Is the socioeconomic gap in childhood exposure to secondhand smoke widening or narrowing? Tob Control. 2013;22(5):344-8.

58. Brenner $\mathrm{H}$, Mielck A. Children's exposure to parental smoking in West Germany. Int J Epidemiol. 1993;22(5):818-23.

59. Ulbricht S, Holdys J, Meyer C, Kastirke N, Haug S, John U. Predictors of indoor smoking at young children's homes-a cross-sectional study. Eur J Pediatr. 2014;173(9):1187-91.

60. du Prel X, Krämer U, Ranft U. Time trends in exposure to environmental tobacco smoke and parental educational level for 6-year-old children in Germany. J Public Health. 2006;14(5):309-15.

61. Conrad A, Seiwert M, Schulz C, Becker K, Ullrich D, Kolossa-Gehring M. German Environmental Survey IV: environmental tobacco smoke exposure of German children. Int J Environ Health. 2008;2(3/4):397-409.

62. Moore GF, Holliday JC, Moore LA. Socioeconomic patterning in changes in child exposure to secondhand smoke after implementation of smoke-free legislation in Wales. Nicotine Tob Res. 2011;13(10):903-10.

63. Longman JM, Passey ME. Children, smoking households and exposure to second-hand smoke in the home in rural Australia: analysis of a national cross-sectional survey. BMJ Open. 2013:3(7):e003128.

64. Lampert T, Kuntz B, Hoebel J, Müters S, Kroll LE. Gesundheitliche Ungleichheit. In: Statistisches Bundesamt (Destatis), Wissenschaftszentrum Berlin für Sozialforschung (WZB), Zentrales Datenmanagement, editor. Datenreport 2016. Ein Sozialbericht für die Bundesrepublik Deutschland. Bonn: Bundeszentrale für politische Bildung; 2016. p. 302-14.

65. Pampel F, Legleye S, Goffette C, Piontek D, Kraus L, Khlat M. Cohort changes in educational disparities in smoking: France, Germany and the United States. Soc Sci Med. 2015;127:41-50.

66. Nagelhout GE, de Korte-de Boer D, Kunst AE, van der Meer RM, de Vries $H$, van Gelder BM, Willemsen MC. Trends in socioeconomic inequalities in smoking prevalence, consumption, initiation, and cessation between 2001 and 2008 in the Netherlands. Findings from a national population survey. BMC Public Health. 2012;12:303.

67. Piontek D, Kraus L, Müller S, Pabst A. To what extent do age, period, and cohort patterns account for time trends and social inequalities in smoking? SUCHT. 2010;56(5):361-71.

68. Kuntz B, Lampert T. Social disparities in maternal smoking during pregnancy. Comparison of two birth cohorts (1996-2002 and 2003-2012) based on the German KiGGS study. Geburtshilfe Frauenheilkd. 2016;76(3): 239-47.

69. Kuntz B, Lampert T. Smoking and passive smoke exposure among adolescents in Germany. Prevalence, trends over time, and differences between social groups. Dtsch Arztebl Int. 2016;113(3):23-30.

70. Sperlich S, Illiger K, Geyer S. Why do mothers smoke? Analyzing the influence of living circumstances and psychological factors on tobacco consumption among mothers with minor children. Bundesgesundheitsblatt Gesundheitsforschung Gesundheitsschutz. 2011;54(11):1211-20.

71. Graham H, Hawkins SS, Law C. Lifecourse influences on women's smoking before, during and after pregnancy. Soc Sci Med. 2010;70(4):582-7.

72. Siahpush M. Why is lone-motherhood so strongly associated with smoking? Aust N Z J Public Health. 2004;28(1):37-42.

73. Kraus L, Piontek D, Pabst A, Gomes de Matos E. Study design and methodology of the 2012 epidemiological survey of substance abuse. Sucht. 2013;59(6):309-20.

74. Hoebel J, von der Lippe E, Lange C, Ziese T. Mode differences in a mixedmode health interview survey among adults. Arch Public Health. 2014;72(1): 46.

75. Robert Koch Institute. German Health Interview and Examination Survey for Children and Adolescents (KiGGS). http://www.kiggs-studie.de/english/ home.html. Accessed 10 May 2016

\section{Submit your next manuscript to BioMed Central and we will help you at every step:}

- We accept pre-submission inquiries

- Our selector tool helps you to find the most relevant journal

- We provide round the clock customer support

- Convenient online submission

- Thorough peer review

- Inclusion in PubMed and all major indexing services

- Maximum visibility for your research

Submit your manuscript at www.biomedcentral.com/submit
Biomed Central 